\title{
SHARED SECURITY: A CHINESE PERSPECTIVE OF NON-TRADITIONAL SECURITY
}

\author{
Dr Imran Ali Sandano* \\ Dr Yu Xiaofengt \\ Dr. Irfan Ahmed Shaik $h^{\ddagger}$
}

\begin{abstract}
Common threat and co-morbid realization have diverted the attention of humans toward non-traditional security studies. The real essence of nontraditional security (NTS) is called 'shared security'. It is not only extension and transformation of security, but it also gives innovation to discourse of NTS studies. The object of shared security is to solve conflicts of human society in general and in diverse conflicts under the Chinese values and contribution in security and diplomacy in particular. Chinese concepts, such as 'bao he tai he' (great harmony are preserve in union), 'wan guoxianning' (states all enjoy response), 'he erbu tong' (harmony but not sameness), and 'tianxia da tong' (unity of the world) all embody rich intellectual resources and the growing discourse on 'shared security'. The Chinese 'Five Principles of Peaceful Coexistence' are the symbol of peace and harmony while the origin of share security provided an important ideological and unique value of the cooperation. The contribution of Chinese scholars and the new concepts like new world, common security, human security and global governance have provided the creative possibilities for sharing security argument. This study attempts to link NTS to common threats and develop shared security within Chinese characteristics.
\end{abstract}

Keywords: Security, non-traditional security; shared security; harmony doctrine.

\footnotetext{
" Assistant Professor, Department of International Relations, University of Sindh, Jamshoro. Email: imran110@usindh.edu.pk (Corresponding Author)

+ Professor, Centre for Non-traditional Security and Peaceful Development, Zhejiang University, China. Email: yuxiaofeng@zju.edu.cn

‡ Assistant Professor, Department of General History, University of Sindh, Jamshoro. Email: irfan.shaikh@usindh.edu.pk
} 


\section{Introduction}

Today humanity is moving towards the depth of 'globalization', 'global survival society', 'global knowledge society', 'global communications society' and 'collective global coexistence.' While the shared consciousness to 'universal threats' and 'survival anxiety' has witnessed 'low politics' and created close links to NTS concept. Since the beginning of the $21^{\text {st }}$ century, people witnessed the September 11 terrorist attacks, severe acute respiratory syndrome (SARS) crisis, the global financial crisis, Japan's nuclear disaster, continuous unrest in West Asia, North Africa, Egypt, Syria, Iraq, Yemen and various other NTS issues. With this wave people have realized that the nontraditional threats are more concerned to security. In order to understand the status of NTS research and the current Chinese security paradigm, we need to go through the origin and evolution of Western NTS theories. Whereas, the Chinese enlightenment, and theoretical paradigm of NTS studies can be operationalized with the concept of 'shared security' that will explore the manifestation of possibility and feasibility in the world context.

The human society and human security development is interconnected. In order to ensure the development of human security, which is fundamental provision for people and can be initiated in different ways like 'shared' or 'self.' Shared security specifically combines a society to respond the wider range of threats. The devastating history and lessons of the World War - I and the World War - II, brought 'peace' into the highest value of human society. Nuclear weapons replaced with Cold War between the major powers - 'invasion' replaced 'deterrence' that enhanced the military preparations later known as Cold War - that increased the chances of 'assured mutual destruction' but also led to the divisions of blocks that prevent the possibility of World War - III. However, the advancement of industrialization and globalization have become the dominant values of human society, so the problems like poverty, over population, environment and energy crisis are constantly 
highlighting the universal threats to humanity. The credit of realization of such issue goes to the bi-polar division, which opened the new chapter of NTS crisis because there won't be complete war or peace, therefore 'security' was directly linked to the threat posed by NTS. What we call it an 'unsafe era' that is coming, mankind must reflect and seek new way of life in order to escape the reality of plight.

The purpose of this paper is to present Chinese perspective of NTS and its compounding concepts like shared security, common security and harmony doctrine. The paper also presents depth analysis of western research trends of NTS studies. The theoretical perspective of shared security under the NTS studies gives importance to security paradigm.

\section{Literature Review}

The concept of NTS produces corresponding theories; these are not only for the theorist's interest but also for fictional research and sometimes used by politicians for political purposes. After globalization phenomena, human recognized the new universal threat and survival anxiety and focused on non-traditional crisis on urgent basis. According to Yunling (2012) NTS issues are not a new phenomenon, they already exist, now these issues are included in the scope of common security and natural reason. In his view, they turn into a 'collective features' type of security with the formation of 'common characteristics', so this issue greatly needs a great attention.

The common threat will inevitably invite the human attention towards NTS and the demand of shared security. Human emphasis on NTS threats originated from issues of non-military concerns. Firstly, during the mid-20 th century onwards, deterioration of ecological environment, population development misconduct, severe poverty and development challenges. Then security research entered into the horizon of the wider issue of terrorism, climate change, energy crisis, food crisis, financial crisis, and issues of information 
security have become important issues of security research. Especially, when the security involved in 'non-state actors' and 'asymmetric' security challenges began to be placed by sub-national and national elements. When an important source of cross-country, global spatial and temporal phenomenon overlapped, then multiple security threats became visible. These sorts of security threats are forcing humans to break the traditional boundary sovereignty and the traditional way of military force. The security research has involved the important areas like, economic, military, political, social and environmental; so social and cultural security have become an important field, therefore, the NTS issues are being given more consideration.

NTS is neither made by single state or group of states nor perceived by a particular country or nation. NTS threats are not only posing mutual threats between nations but bring all the nations of the world under threats. The NTS threats are not like traditional national security threats, it is by thinking how to deal with the issue of another country, but these threats are challenging all the developed, developing and under developed countries. NTS issues are emphasizing on to think that how to work together to address such common security threats (Yaqing, 2013). From domestic NTS threats to international security threats, all require an internationalization of these threats that come to reflect and construct comprehensive security strategy for all humans.

The term 'NTS' was first coined during the Cold War era by the western intellectuals of international security and international relations. Distinguished Professor Richard H. Ullman of international relations at Princeton University published an article in an International Security Journal in 1983 with the title of 'Redefining Security (Ullman, 1983), in which he wrote about human poverty, disease, natural disasters, environmental degradation etc. he was the first person who gave a new direction to rigid traditional security. Since then, some of the emerging theories of international relations, 
especially in environment, economics and political science were introduced; scholar of international political started expanding the field of NTS studies. Construction of NTS studies has made many contributions and become an important academic source for western researchers.

Currently, the institutionalization of NTS studies is on rise, it has been taught as course in universities and colleges and research topics related to NTS are common now. On the other hand, opening of NTS research institutions maintain the influence of the subject. These research institutions are spreading the awareness about NTS challenges into messes in different ways such as publications (including journals and monographs), papers, websites, seminars, conferences and media reports. It should be noted that, Western scholars used NTS studies specifically in security research such as environmental security, economic security, energy security and food security, which are burning issues of other countries and regions of the world (Buzan \& Hansen, 2009).

In year of 1999, the first article 'On the economic security from the perspective of non-traditional security view' published in China discussed NTS (Mengzi, 1999). In 2003, the CASS Institute of World Economy and Politics organized a nationwide series of seminars on NTS and the series of books started publishing on it. Accordingly, a number of NTS research institutes were established, and Chinese universities and colleges also offered NTS programmes with special introduction to doctoral and master's degree programmes in the field. It transformed Chinese NTS studies into the establishment of subject and personnel training centres for institutionalization.

Since the beginning of $21^{\text {st }}$ century, Chinese scholars started working on the nature, characteristics, types and other theoretical aspects of NTS studies. It comparatively focuses on traditional security, domestic security, NTS, and international security thoroughly with the Chinese strategy of mutual transformation of NTS settings. 
Human security maintenance thinking has different patterns, but theoretical view of NTS is a new security phenomenon for understanding and interpretation with many differences. Some scholars of the NTS defined it as a 'revolution of security' (Zhongyi, 2004) and comprehended as a 'China's peaceful rise on the social basis,'(Yizhou, 2004) 'human and social security' on the bases of new security context, (Yizhou, 2003) a 'new opportunity to expand,' (Zhongwei, 2003) the 'new security concept of China' (Yong, 2007) and 'the new heights of Chinese diplomatic cooperation' (Yizhou, 2008). While others have called it as a 'methodology, epistemology and transformation of security research from single discipline into a multidisciplinary approach (Yuanliang, 2011) and considered as new security platform that promotes new talent in education and training, at colleges and universities (Xiaofeng, 2012).

The core of the traditional concept of security is getting deeper into common security from national security, global security and human security, through profound transformation from military and political security. It has become an extendable area, which links to human, social and political security. Military strategist believe that, military deals with antiterrorism campaign, system chaos, disaster relief, peacekeeping, combating transnational crimes and other nonwar military operations, it ensures people to live and work in social environment with a stable protection, economic development, national interests, extended support as well as world peace (Xu, 2009). Academicians respectively have formed the comprehensive framework of 'collective security', 'global security', 'human security', 'social security', environmental security', 'economic security' and other NTS perspectives to explore the uniqueness and importance in policy making process. China as a rising power has explored the idea that how China is inclusive to the world and how to make the world tolerant to China. Scholars reached on basic consensus, that NTS is transforming humans to seek a win-win common speech, to make a reasonable deal with the challenges of NTS issues, as necessity to 
secure a new theoretical reflection and construction.

\section{Methodology}

This research study is carried out using qualitative research approach based on the interpretative content analysis, to gain more qualitative understanding of the issues pertaining to the shared security and Chinese perspective of NTS. This study has gone through an extensive study of documents and communication artefacts, texts of various formats. The content was thoroughly analysed through the interpretation of codes and textual materials to analyse and examine the patterns of communication.

\section{Construction of Security}

Western NTS studies extended from the traditional security studies and peace studies has further expanded and transformed in different regions of the world. British scholar Barry Buzan (2009) believes that the evolution of security research development defined in such context: the transformation of international security studies and postCold War gave the emergence to the two camps, one is peace and strategic studies re-integrated into the post Cold traditionalism and other is from the 1970s and 1980s peace studies, extended and deepened faction (including constructivism, post-colonialism, human security, critical security studies, feminism, and Copenhagen School after structuralism), which became the main source of NTS studies.

Western NTS theory, built up a referent object, differs from traditional security. The national centric security studies conducted critical doctrine, in addition to human security and individual security concerns; more attention was paid on development issues including poverty and hunger issues where low politics was involved. The postcolonial Western-centric discourse reflects the security profound and criticism. The NTS theory is referred to involve object in a safe and secure way to achieve security research methods and other 
aspects of new theoretical innovation, especially, critical security theory, human security studies, feminist security studies and poststructuralism doctrines. These doctrines are beyond the traditional and national security studies standard and pursuit of human security. Its orientation is very obvious and strong, making the Western NTS theory as a new perspective, scope, content and features.

\section{Evolution of NTS Studies in China}

The western 'atomism' thinking mode and 'dualism' methodological stance, quite different from the Chinese 'relationship doctrine' and 'holism', formed the unique stance of Chinese security thinking. To compare China with the West, Kissinger (2012) presents the Chinese two-player strategy (chess). He believes in chess victory, the security and strategic level of Chinese thinking is far better than its 'mutual coexistence'. In fact, Chinese history has three dimensions of shared security through the feasibility of exploration and practice with both wealth and resources. Chinese rich security thinking history has 'shared security' which provides rational construction and value that coordinates security theory. It provides a rationale to maintain the characteristics of the Chinese diplomatic security practices through the concept of shared security which provides a unique example of the feasibility.

\section{Shared security: an ideological origin}

Shared security ideological origin can be traced back in ancient China's 'co-existence theory' and 'theory of harmony', which has been representative in the Book of Changes. Book of Changes clearly presents the 'maintenance of great harmony' (bao he tai he) (Wilhelm \& Baynes, 1950), it gives value to security objectives, and 'universal response'(wan guoxianning) (Wilhelm and Baynes, 1950). It gives ideals of shared security (Tang, 1998) and 'make universal peace' (xi he wan bang) and provides the security implementation path. 'Great harmony' is an ideal realm of social security with easy meanings. The 
book contains the philosophical study of nature of being, which clearly reflects the values of five different meanings, easy, simple, not easy, transactional and vulnerable (Xiaofeng, 2013).

'Great harmony' is a philosophical characterization of the security implication, which stands for self-reliance, spirit virtue and perfect unity. It reflects the Chinese traditional culture and harmony and feeling for others that creates a perfect principle of coordination (Xiaofeng, 2013).It has long history which stressed on the 'unity of the world'(tianxia da tong) which gave importance and strength to the Chinese people. The traditional Chinese society builds the 'unity of the world' concept with later known as 'shared security'. Shared security is considered as the most basic structural element of stability, which has contents of both geopolitical and cultural connotations with security distinction. Western scholar William A. Callahan says that, to achieve a 'common ground' (he erbu tong: harmony but not same) state has the inherent logic of a flexible methodology, through the use of differences in ambiguity and correct interpretation (Callahan, 2004). Zhao Tingyang (2007) says that there might be difference between the states of the world, that may cause the conflict, but there are at least two solutions: First is to eliminate the differences on such issues, which are unified, this solution is not desirable, because this does not follow another order. The second one looks at differences and build collaborative relations to maximize mutual interests (Tingyang, 2007). So, to reach a 'common ground' and 'great harmony' in the world, there are fundamental contents of Chinese thinking, like 'existence to coexistence' and 'existentialism' with different identities (Tingyang, 2007).

\section{Peace and harmony: Shared security to explore the possibility}

Shared security is possible addition into the mining history of ideological resources; it also needs theoretical consideration for the current world security environment. In China, the modern contemporary scholars are striving to explore the ideal human 
security and globalization from different angles of NTS studies. There have been many emerging harmony doctrines and models associated with valuable security thinking that result and explore the 'shared security' in the different perspective of the current world.

\section{Shared Security: Explores the global security}

Wang Yizhou (2013) explored the outlook of global security perspective under the doctrine of global politics and interpreted the Chinese diplomacy with compassionate hegemony. He integrated Chinese creative intervention concept with the world politics. He believes that the security and expectations depend on the extent of traditional national security issues, emerging social security issues and accommodating a variety of actors outside the country, which hold global common good and human security. He stressed that 'new security' must be included in both national security and various nonstate actors, including common security and balanced security, thus the 'new security' is phenomenon of the globalization which need mutual or shared security (Yizhou, 2003). Wang Yizhou's depth study on Chinese diplomacy and its role in global politics generated debate that how Chinese policy is different from other leading actors of the world (Yizhou, 2013).

China has proposed six intervening programmes for avoiding direct confrontation, such as, resolving the Taiwan issue on the basis of medium-range schema of both sides; breakthrough in Sino-Japan sea dispute through dialogue with American and Japanese; and two distinguished linked ideas, new China-Africa cooperation under the concept of 'China-Africa new partnership' and so on (Yizhou, 2013).These thoughts are reflection of 'shared security' which may establish new values for formulating policy. Zheng Xianwu advocates the regional approach in Southeast Asian states under 'pluralistic security community' which reveals that the history and evolution of regional states can encourage and 'collective internal security' approach to 'defensive community' and then to 'comprehensive and 
cooperative security' with strong security mechanism. This model is quite appropriate for ASEAN nations.

\section{The transformation of Chinese concept of 'shared security'}

Yan Xuetong (2013) disagreed with the hegemonic order of the world. He believes that disagreement between the states should be solved in the peaceful manners and stresses that there is a need of 'good will' to promote international practice of justice and new relations between big powers and to enhance political soft power. Ancient Chinese 'good will' and 'great harmony' proprieties are similar to the modern equity, justice and civilization and these three are higher than equality, democracy, freedom and values. Chinese trends and traditions of political thoughts can be the essence of globalization and also guide to construct new international norms (Xuetong, 2013). Zhao Tingyang (2007) has given an idea of Chinese 'cooperation game' based on a complete dialogue to conduce cooperation among nations. He attaches great importance to the world and its transformation with global perspective. He believes that Chinese way of universal thinking is capable for globalization and new world system. According to his view, 'you' can share happiness of the world that is inclusive and does not exclude any person, but try to turn other one to 'you.' This would create a peaceful world without enemies (Tingyang, 2007).

Ren Xiao (2013) has opposed 'Chinese world order' and proposed the association of shared cooperation between East Asian countries with symbiosis approach. He believes in symbiosis approach (living is close and often long-term interaction) which is soft and flexible structure under internal order and characteristic of East Asian countries. It doesn't matter, either a country is small or big, when there is a good political and economic understanding among the countries and they remain on the same page for a regional peace and stability (Xiao, 2013). The fundamental elements of symbiotic approach describe mutual recognition of various exchanges, 
reciprocal tributary trade, voluntary exchange of resources, and symbiotic type of identity and construction (Xiao, 2013).

\section{Global security governance: A path to explore 'shared security'}

Qin Yaqing (2013) has presented a positive view of globalization and stressed on the use of pluralistic, corporative, global and effective governance. He strongly opposed the traditional interest and monopoly governance and monopoly and hegemonic governance. Pang Zhongying (2014) proposed the idea of global governance to promote the practice of current international law as a global law; and United Nations General Assembly was transformed into a world assembly in order to strengthen the global governance. Li Dongyan (2013) highlighted the post-Cold War global security threat and proposed the concept of global security governance, which mainly identifies the global security threats and challenges, the need for global arrangements system to promote common strategies, decisions and actions with a variety of stakeholders and participants (governments, international organizations, multilateral groups, nongovernmental organizations, business enterprise sector and the mass media). Meanwhile, he proposed the corresponding concepts of 'security management' and 'core security governance' in the sphere of NTS and touched the financial, energy, food security and environmental issue (Dongyan, 2013). Through global security governance, China and other states with international organizations can promote positive security partnership, cooperation, reconciliation and harmony at both, global and regional levels (Dongyan, 2013). Tang Wei proposed the 'Earth System governance' concept, Li Shuyun (2011) proposed the 'sustainable security governance' program and Zhang Shengjun (2013) proposed 'depth of global governance' strategy. 


\section{Chinese strategy selection and 'shared security'}

Yang Jiemian (2012) in his theoretical research on 'diplomatic preparation of China to become a Global power' describes that China has a potential global power diplomacy theory and its ultimate objective is to achieve the peaceful coexistence and harmony in the world. He believes that, if human society can grasp the historic opportunity, perhaps the history of human civilization can be achieved through peaceful means with the help of symbiotic global power and win-win concepts. Wang Yiwei (2011) from beyond the 'peaceful rise' concept, proposed the 'comprehensive rise' concept. He believes that both security and development are in the same context, and the peaceful rise of China needs to establish modern methods to develop relations with the world. Historical experience emphasizes on the establishment of global altruistic concern about the future and 'comprehensive rise' which benefits win-win, symbiosis of power, shared responsibility, and shared values concepts. Therefore, comprehensive rise strategy is to dilute the essence of the Chinese model and building common security mechanism for the world in general. The world can be beneficial from the rise of China with power and responsibility sharing, which is comprehensive development of China.

\section{Discussion}

There are many other quite innovative thinking and pioneering theories of 'shared security' to explore the certain possibilities. In a nutshell, whether it is 'common security act', 'common human security', 'comprehensive rise', 'common security', 'cooperative security', 'pluralistic security community', 'harmony', 'security construction', 'new world doctrine', 'East Asian symbiosis', 'global Security governance' or 'Earth System governance' all give the interpretations of Chinese perspective on NTS strategy and are keen to explore and solve the crisis of human beings. Chinese historical reflection and characteristics of 'great harmony', 'security 
philosophy' and 'harmony doctrine' reflect the 'shared security' as a security cohesion era of globalization which also express the human spirit in universal characteristics.

NTS is universal, composite and multidimensional area of study. While the traditional security is creating more and more NTS issues, risks, crisis, and a state of emergency that makes national, human, social and global security threats, which are often fused and intertwined with the mutual understanding and conversion. However, the historical and theoretical dimensions are showing the feasibility of 'shared security' in real sense. Especially, where there is conflict of interests between states on issues like, distribution of resource, boundary disputes, domestic crisis, social unrest, refugees and mass events; at this point many scholars, particularly foreign scholars ask about the 'share security' and Chinese NTS studies.

At the first glance, NTS threats have realistic look of security identity and varying degrees of security dilemma. Resource development measures of a State use to be taken to protect, it would be regarded as a relative decrease of utilization of its resources in other countries, because of 'tragedy of the commons' arising from the insecurity in the content of NTS dilemma. This requires rethinking global public good that provides pleasant process of re-exploring new nature of 'national sovereignty' relations. It can be called 'conditional and responsible sovereignty' (Glanville, 2013) that is shared between the states to promote and implement or properly transfer sovereignty to global governance beyond the NTS dilemma. Chinese scholar Zhang Shengjun (2013) believes that the 'responsible sovereign' should be mutual and reasonable; otherwise the national development of the country will become imbalance to achieve real 'global governance'. It needs to promote mutual responsible sovereignty and mutual dependency with reciprocal responsible sovereignty based on real 'global governance' where states can easily address their common crisis. 
'Shared security' must go beyond the current disagreed international community. The notion of conflict security, contradiction on security strategy and institutional security policies should be dealt with the motive of human survival environment and the global NTS challenges. It can be happened when states 'build' and 'share' security. It is most difficult part that reflects how states will share security in different existing levels of homogeneity factors. The states are considered civilized, cultured, religious, national, and social; all diversities are based on historical and geopolitical interests, resources, systems, methods and even misunderstanding that caused conflict, confrontation, misunderstandings and transformation. This wave is presenting different picture of future directions of share security concept. However, throughout the human social history and development, we undoubtedly find that it is a common threat that continues to expand the scope of human existence under challenging scenarios resulting into the widespread human society constantly experiencing efforts to achieve a small community. Homogeneity sharing is difficult, even gradually advancing towards tolerant heterogeneity of the larger global community until the process of sharing is achieved.

Realistic security studies raised many of the international security concepts such as, 'deterrence and nuclear deterrence theory', 'geopolitics theory', 'balance of power theory', 'game theory', 'theory of security dilemma' and 'hegemonic stability theory' etc. These security concepts are not only based on self-interests and power orientation, but also emphasize on homogeneous interests of sharing. Liberal security studies are widening contacts between the state and the growing trade and economic integration. The 'interdependence theory', 'democratic peace theory' and other security concept based on economic and diplomatic integration are trying to create a new international security situation within international system. Constructivist security studies emphasizes on the 'social relations' to specify the role of the state, 'social identity' building national security 
interest, 'social culture' influencing national security strategy, and 'social norms' to create security model. Alexander Wendt (1992) presented constructivism as 'self-guided power politics, which is not necessarily characterized as anarchy, rather anarchy is created by the state. This results into 'social identity' and its complete concept has become a fundamental variable of security, even though a country that tend to pursue its own interests, in true sense its benefits are also driven by the national recognition. Its interpretation, meaning and decision should be defined as subjective security interests (Wendt, 1992).

Chinese 'shared security' has its own unique efforts and contributions. It is following 'five principles of peaceful coexistence' in international relations to solve all the disputes including The Senkaku Islands dispute with Japan. By following 'shelving sovereignty and common development' principle, it has done reunification of Hong Kong under 'one country two systems' policy. Chinese NTS theory proposed the 'mutual benefit', 'mutual trust' and 'equality and cooperation' these contents are the core content of the Chinese 'new security concept.' This concept stresses on civilizations' diversity, sharing and cooperation in the premise of a 'harmonious society' and 'world harmony' strategy. In today's world, peaceful rise of emerging powers and their relations are important topics. Since different countries have different history, cultural, heritage, values and civilizations, so they are pursuing full value of 'homogeneous' between the great powers and 'heterogeneous' phenomenon and how to set up secure interaction between the great powers in such a complex reality? At this end, Chinese leadership recently proposed important principles and approaches, like no conflict, no confrontation, mutual respect, positive interaction, cooperation and win-win to address power relations through which major powers achieve shared security in diplomatic path (Yang, 2013). 


\section{Conclusion}

In fact, since the $20^{\text {th }}$ century, the international community has coined many approaches, like 'collective security', 'integrated security', 'consultative security', 'common security', 'cooperative security' and many others. Security theory, security policy and security governance have been dealt in different levels to seek and practice some kind of 'shared security'; especially the 'cooperative security' is a big degree to solve NTS issues. The objective of 'shared security' is to provide some evidence of reality, but at the end, it does not get rid of security practice from limited state actors. The 'shared security' depicts the human community centres as a secure position to protect human life and provide security, for peace and prosperity in the society, in order to build a harmony and win-win cooperation between countries as a supreme principle of national security doctrine. 'Shared security' is not a common and different in quality yet different in responsibilities; it not only enjoys democratic based legitimacy but it also enjoys justice based legitimacy (Xuetong, 2013).

In short, 'shared security' is to enhance the partnership between the states, which further promotes and creates the win-win cooperation. The increasingly integrated world is also a gesture of 'shared security' that shows both ideal and realistic based formation. The sharing values lies over the premise of survival resources of shared actors and living conditions, with common identity. While the constructing winwin situation is prerequisite for the feasibility of 'shared security' that ultimately reflects pluralism to build unopposed constructive strategy (Jun, 2013).Thus, the 'shared security' is an act of state that would have a unilateral position beyond inseparable and multilateral factors. It is beyond the crisis and confrontation, and has self-interest that owns global responsibility to promote the interest of incremental security of the world. It is good to say that 'shared security' is not only an important part of a world harmony but it is also an important part of Chinese dream, because China hopes to work with countries by win-win cooperation and common development. 


\section{References}

Buzan, B., and Hansen, L. (2009). The evolution of international security studies. Cambridge University Press

Callahan, W. A. (2004). Remembering the future-utopia, empire, and harmony in $21^{\text {st }}$ century international theory. European Journal of International Relations, 10, 569-601

Dongyan, L. (2013). Global security governance and China's choice. World Economics and Politics, 42-54

Glanville, L. (2013). The myth of 'traditional' sovereignty. International Studies Quarterly, 57, 79-90

Jiemian, Y. (2012). China diplomatic theory to prepare a global power. World Economics and Politics, 10-21

Jun, X. (2013). Neutral and non-institutional cooperation in BRIC countries. World Economics and Politics, 92-116

Kissinger, H. (2012). On China. UK: Penguin Books

Mengzi, F. (1999). On the economic security from the perspective of nontraditioal security. Contemporary International Relations, 4, 2-16

Shengjun, Z. (2013). Target depth and prospects for the global governance. World Economics and Politics, 55-75

Shuyun, L. (2011). Environmental change may continued to security building. World Economics and Politics, 112-135

Tang, HCaKA. (1998). Brief account and other justice. Hangzhou: Zhejiang Ancient Books Publishing House

Tingyang, Z. (2007). Conflict, Cooperation and harmony: A game of philosophy. World Economics and Politics, 15-23

Ullman, R. H. (1983). Redefining security. International Security, 8, 129-153

Wendt, A. (1992). Anarchy is what states make of it: The social construction of power politics. International organization, 46, 391-425 
Wilhelm, R., and Baynes, C. F. (1967). The I ching or book of changes. Princeton University Press

Xiao, R. (2013). East Asia symbiosis principle. World Economics and Politics, 422

Xiaofeng, Y. (2012) China non-tradiontal security (Research Report 20112012). Beijing: Social Sciences Academic Press

Xiaofeng, Y. (2013). Security triple ideal interpretation of chinese society, Urmuqi: Xinjiang Normal University

Xu, S. X. (2009). The army deal with non-traditional threats to security research, Beijing: Military Science Press

Xuetong, Y. (2013). Diplomacy principles of fairness and justice, values and win-win cooperation. International Studies: 7-14

Yang. (2013). Under the new situation of China's diplomatic theory and practice of innovation, Xinhua

Yaqing, Q. (2013). The concept of global governance failure and order reconstruction. World Economics and Politics, 6-7

Yizhou, W. (2003). The importance of non-traditional securrty studies. People's Daily

Yizhou, W. (2003a). Global politics and chinese diplomacy. Beijing: World Knowledge Publishing House

Yizhou, W. (2004). China and non-traditional security. International Economic Review, 43-57

Yizhou, W. (2008). Chinese foreign new heights, Beijing: China Social Sciences Press

Yizhou, W. (2013). Creative intervention - china's global role. Beijing Peking University Press

Yong, F. (2007). Non-traditional security and China. Shanghai: People's Publishing House.

Yuanliang, Z. (2011). NTS and Chinese diplomacy new strategy. Beijing: China Social Sciences Press 
Yunling, Z. (2012). China on-traditional security (Research Report 2011-2012). Beijing: China Social Sciences Academic Press

Zhongwei, L. (2003). Non-traditional security theory. Beijing: Current Affairs Press

Zhongyi, H. (2004) Symposium of non-traditional security and China. The World Economy and Politics, 2, 48-55

Zhongying, P. (2014). Global government: A fundamental and effective means of global governance. International Observers, 16-22 